\title{
Prediction of Response to Neoadjuvant Chemotherapy: New Biomarker Approaches and Concepts
}

\author{
Carsten Denkert $^{\mathrm{a}} \quad$ Bruno Valentin Sinn $^{\mathrm{a}}$ Yasmin Issa $^{\mathrm{b}} \quad$ Berit Maria Müller $^{\mathrm{a}}$ \\ Andrea Maisch ${ }^{\mathrm{b}}$ Michael Untch $^{\mathrm{c}}$ Gunter von Minckwitz ${ }^{\mathrm{b}}$ Sibylle Loibl ${ }^{\mathrm{b}}$ \\ Institute of Pathology, Charité Universitätsmedizin Berlin, \\ ${ }^{\mathrm{b}}$ German Breast Group, Neu-Isenburg, \\ 'Helios Klinikum Berlin-Buch, Germany
}

\section{Keywords}

Neoadjuvant · Chemotherapy · Breast cancer . Lymphocytes · PARP

\section{Summary}

About $10-25 \%$ of breast cancer patients achieve a pathologically confirmed complete response after neoadjuvant chemotherapy. Tissue samples of pretreatment core biopsies are a valuable resource for translational research aiming towards predictive biomarkers for selecting patients who are likely to benefit from neoadjuvant therapy. The German Breast Group (GBG) and the AGO-B Group (AGO = Working Group Gynecological Oncology) have extensive experience in conducting neoadjuvant clinical trials. Technologies as immunohistochemistry on tissue microarrays and standardized reverse transcription-polymerase chain reaction (RT-PCR) approaches on formalin-fixed paraffin-embedded samples allow high-throughput investigation of protein and mRNA biomarkers. With these approaches, we could demonstrate that molecular tumor subtypes and immunological infiltrates are valuable and independent predictors of therapy response. New biomarkers such as poly(ADP-ribose) polymerase (PARP) might be useful for the prediction of response to conventional and new targeted therapies. This review summarizes current research projects focusing on biomarker discovery in the neoadjuvant setting.

\author{
Schlüsselwörter \\ Neoadjuvant - Chemotherapie - Mammakarzinom . \\ Lymphozyten · PARP
}

\section{Zusammenfassung}

Etwa 20-25\% der Patientinnen mit Brustkrebs erreichen nach einer neoadjuvanten Chemotherapie ein pathologisch bestätigtes komplettes Ansprechen. Prätherapeutische Stanzbiopsien sind eine wertvolle Quelle für translationale Forschungsprojekte mit dem Ziel, neue prädiktive Biomarker zu finden. Ziel ist eine individualisierte und verbesserte Therapie für die Patientinnen. Die German Breast Group (GBG) und die Arbeitsgemeinschaft Gynäkologische Onkologie (AGO)-B Group haben langjährige Erfahrung bei der Durchführung neoadjuvanter klinischer Studien. Technologien wie die Immunhistologie anhand von Tissue-Microarrays und standardisierte Ansätze mittels reverse-Transkription-Polymerase-Kettenreaktion (RT-PCR) an formalin-fixiertem Paraffingewebe erlauben die Untersuchung von Biomarkern auf Protein- und mRNA-Ebene mit hohem Probendurchsatz. Mittels solcher Ansätze konnten wir zeigen, dass die molekularen Tumortypen und das immunologische Infiltrat bedeutende und unabhängige Prädiktoren des Therapieansprechens darstellen. Neue Biomarker wie Poly(ADP-Ribose)-Polymerase (PARP) könnten dazu dienen, das Ansprechen auf eine konventionelle Chemotherapie und neue zielgerichtete Therapien vorauszusagen. Die vorliegende Übersichtsarbeit fasst die aktuellen Forschungsprojekte mit dem Ziel der Biomarkerentdeckung in der neoadjuvanten Situation zusammen.

\section{KARGER \\ Fax +497614520714 \\ Information@Karger.de}

www.karger.com (c) 2011 S. Karger GmbH, Freiburg

$1661-3791 / 11 / 0064-0265 \$ 38.00 / 0$

Accessible online at:

www.karger.com/brc
Prof. Dr. med. Carsten Denkert

Institut für Pathologie der Charité Campus Charité Mitte

Charitéplatz 1, 0117 Berlin, Germany

Tel. +49 30 450-536047, Fax -536902

carsten.denkert@charite.de 


\section{Introduction}

Breast cancer is the most common cancer in women worldwide with more than 1.1 million women diagnosed annually [1]. Each year, more than 200,000 new breast cancer cases are expected in the USA [2]. In Germany, an estimation of more than 60,000 cases per year has been reported for the last decade [3].

Primary non-metastatic breast cancer is accepted as a systemic disease with a local-regional component and therefore needs to be treated by systemic therapy as well as by local procedures such as surgery and radiotherapy. A metaanalysis by Mauri et al. [4] demonstrated identical effectiveness of neoadjuvant and adjuvant chemotherapy in terms of diseasefree survival (DFS) and overall survival. Therefore neoadjuvant chemotherapy should be discussed with all patients who are candidates for adjuvant chemotherapy at the time of primary diagnosis [5].

Three main objectives of neoadjuvant therapy can be defined: improvement of surgical options, both to reach operability in primary inoperable tumors and to improve surgical options in primary operable cancers; to improve outcome by reaching pathologic complete response ( $\mathrm{pCR}$ ); and to obtain information on mid-course response, which might help to further tailor the treatment [6]. pCR, which implies an eradication of all viable tumor cells, is an important prognostic factor that could be demonstrated concordantly in several clinical trials [7-9]. Thereby, the definition of pCR varies between the different studies. The more restrictive the definition, the lower is the pCR rate but also the more favorable is the outcome of the pCR group [10]. Especially the subgroups of human epidermal growth factor receptor 2 (HER2)-positive breast cancer and triple-negative breast cancer (TNBC) can be discriminated by pCR into a group with an excellent prognosis and a group with a less favorable outcome [11, 12]. In the luminal A and probably in some patients in the luminal B group, the outcome is independent of the pCR [10]. In these groups we need to find other markers to indicate long-term profits from systemic treatment.

However, first we still do not know who will exactly benefit from chemotherapy \pm biological treatment. Even in the more chemosensitive subgroups (TNBC and HER2+) a great proportion of patients do not reach a $\mathrm{pCR}$. We need more precise tests that will indicate responsiveness to primary systemic treatment prior to the start of treatment. Neoadjuvant therapy offers a good opportunity to reach this goal.

\section{Clinical Concepts and S tudies}

The German Breast Group (GBG) and the AGO-B Group (AGO = Working Group Gynecological Oncology) have a long tradition of undertaking neoadjuvant studies (table 1). 3 trials investigated the dose-dense concept (GeparDuo,
AGO1, PREPARE), which demonstrated that the dose-dense concept is only superior if the chemotherapy is given long enough. Duration of chemotherapy is important and was recently demonstrated by a metaanalysis based on the German neoadjuvant trials. Every 2 additional cycles of chemotherapy improved the pCR rate by approximately $20 \%$. This seemed less important for TNBC and more important for luminal tumors [13].

The GeparTrio and the current GeparQuinto trial investigated the concept of tailoring therapy according to mid-course response. The GeparTrio trial randomized patients according to their response after the initial 2 cycles of docetaxel/doxorubicin/cyclophosphamide (TAC) to further 4 cycles of TAC or switch to a non-cross-resistant chemotherapy with vinorelbine and capecitabine in the non-responder group and further 4 or 6 cycles of TAC in the responder group [14-16]. It could be demonstrated that the responder group has a much higher pCR rate than the non-responder group, but there was no significant difference between the arms within the nonresponder and responder patients. However, long-term results have to be awaited.

The GeparQuinto trial investigated the addition of bevacizumab to epirubicin/cyclophosphamide-docetaxel (EC-Doc) in the HER2- setting, and those not responding after EC \pm bevacizumab were again randomized to receive in addition paclitaxel weekly \pm the mTOR inhibitor RAD001 (mTOR = mammalian target of rapamycin) [17]. The initial analysis revealed only a benefit in the subgroup of TNBC, but the final analysis still has to be performed. This is somewhat in contrast to recent data from the NSABP-B40 trial presented at the American Society of Clinical Oncology (ASCO) meeting 2011, which demonstrated a benefit in the hormone receptor (HR)positive patients $[18,19]$. The HER2+ patients received, in addition to EC-Doc, either trastuzumab or lapatinib, without further separating the groups according to mid-course response [20]. Data from Neosphere and Neo-Altto demonstrated that the double anti-HER2 blockade is significantly better. However, comparing the data, the pCR rate with a 12-week monochemotherapy plus double anti-HER2 blockade was as good as 24 weeks of polychemotherapy with trastuzumab. A longer polychemotherapy in addition to a double anti-HER2 blockade is probably better, as shown by recent data [21].

The results suggest that we need better predictors for response and resistance to neoadjuvant therapy for HER2+ treatment and also for anti-angiogenesis in addition to chemotherapy. Markers for trastuzumab resistance so far revealed contradictory results for p95 [22] and phosphatase and tensin homolog (PTEN) [23, 24]. New markers as eucariotic translation initiation factor 4E-binding protein 1 (EBP41) and aldehyde dehydrogenase (ALDH) might be of interest [25]. The RESPONSIFY project funded by the European Union (EU) within the 7th frame program (FP7; coordinator Sibylle Loibl, GBG) will aim to find biomarker tests to better select the patients for anti-HER2 and anti-angiogenesis treatment. 
Table 1. Overview on clinical trials of the GBG and AGO

\begin{tabular}{|c|c|c|c|}
\hline Trial & Therapy & $\mathrm{n}=6634$ & урT0/Tis; ypN0 \% \\
\hline \multirow[t]{2}{*}{ Gepardo } & ddADoc $\times 4$ & 126 & 9.5 \\
\hline & ddADoc $\times 4+$ Tam & 122 & 5.7 \\
\hline \multirow[t]{2}{*}{ GeparDuo } & ddADoc + Tam & 453 & 10.2 \\
\hline & $\mathrm{AC} \times 4-\mathrm{Doc}+\mathrm{Tam}$ & 454 & 19.2 \\
\hline \multirow{2}{*}{ GeparTrio Pilot } & $\mathrm{TAC} \times 6$ & 252 & 19.0 \\
\hline & $\mathrm{TAC} \times 2-4 \times \mathrm{NX}$ & 33 & 6.1 \\
\hline \multirow{3}{*}{ GeparTrio } & $\mathrm{TAC} \times 6$ & 1055 & 19.1 \\
\hline & $\mathrm{TAC} \times 8$ & 686 & 29.0 \\
\hline & $\mathrm{TAC} \times 2-4 \times \mathrm{NX}$ & 331 & 6.9 \\
\hline GeparQuattro & $\mathrm{EC} \times 4-\mathrm{Doc} \times 4$ & 343 & 18.7 \\
\hline HER2- & $\mathrm{EC} \times 4-\mathrm{DOCX} \times 4$ & 345 & 16.5 \\
\hline \multirow[t]{2}{*}{ HER2+ } & $\mathrm{EC} \times 4-\mathrm{Doc} \times 4-\mathrm{X} \times 4$ & 362 & 19.1 \\
\hline & $\mathrm{CHT}+$ trastuzumab & 445 & 41.3 \\
\hline \multicolumn{2}{|l|}{ GeparQuinto } & \multicolumn{2}{|l|}{2582} \\
\hline HER2 - setting I & EC-Doc \pm bevacizumab & 1948 & \multirow{3}{*}{$\begin{array}{l}20.3 \text { vs. } 18.5 \\
45 \text { vs. } 29.9\end{array}$} \\
\hline HER2- setting II & $\mathrm{Pw} \pm \mathrm{RAD} 001$ & \multirow{2}{*}{$\begin{array}{l}\text { still recruiting } \\
620\end{array}$} & \\
\hline HER2+ setting III & EC-Doc + T vs. EC-Doc $+\mathrm{L}$ & & \\
\hline \multicolumn{4}{|l|}{ GeparQuinto } \\
\hline \multirow{2}{*}{ AGO 1} & $\mathrm{EP} \times 4$ & 335 & 6.6 \\
\hline & $\mathrm{ddE} \times 3-\mathrm{ddP} \times 4$ & 333 & 13.2 \\
\hline \multirow{2}{*}{ PREPARE } & $\mathrm{EC} \times 4-\mathrm{P} \times 4$ & 370 & 14.6 \\
\hline & $\mathrm{ddE} \times 3-\mathrm{ddP} \times 3-\mathrm{CMF}$ & 363 & 20.4 \\
\hline TECHNO & $\mathrm{EC} \times 4-\mathrm{PH} \times 4$ & 226 & 40.7 \\
\hline \multicolumn{4}{|c|}{$\begin{array}{l}\text { ypT0/Tis = no invasive residual tumor, only non-invasive residual tumor; ypN0 = no residual tumor in lymph nodes; ddADoc = dose-dense doxorubicin/ } \\
\text { docetaxel; Tam = tamoxifen; } \mathrm{AC}=\text { adriamycin/cyclophosphamide; } \mathrm{Doc}=\text { docetaxel; } \mathrm{TAC}=\text { taxotere/adriamycin/cyclophosphamide; } \mathrm{NX}=\text { vinorelbine/ } \\
\text { capecitabine; } \mathrm{EC}=\text { epirubicin/cyclophosphamide; } \mathrm{DOCX}=\text { docetaxel/capecitabine; } \mathrm{CHT}=\text { chemotherapy; } \mathrm{PW}=\text { paclitaxel weekly; } \mathrm{X}=\text { capecitabine; } \\
\mathrm{T}=\text { docetaxel; } \mathrm{L}=\text { lapatinib; } \mathrm{EP}=\text { epirubicin/paclitaxel; } \mathrm{ddE}=\text { dose-dense epirubicin; } \mathrm{ddP}=\text { dose-dense paclitaxel; } \mathrm{CMF}=\text { cyclophosphamide/methotrexate } / 5 \text { - } \\
\text { fluorouracil; } \mathrm{PH}=\text { paclitaxel/trastuzumab. }\end{array}$} \\
\hline
\end{tabular}

\section{Translational Research and Tumor Banking in the Neoadjuvant Setting}

Tissue samples from clinical trials are a valuable resource of translational cancer research with the goal of predictive or prognostic biomarker discovery to improve clinical management of future generations of patients. Translational research projects are often multi-disciplinary multi-center projects that are critically dependent on optimal biobank organization and the continuous collection of tissue samples. This should be performed in parallel to the conduction of the clinical studies. The informed consent as a prerequisite for sample collection and biomarker assessment is an important element of the clinical study setup. The GBG and the AGO-B Group are currently collecting tissue samples from all neoadjuvant, adjuvant and metastatic studies. These samples are stored in the GBG tumor biobank at the Institute of Pathology, Charité Hospital (Berlin, Germany). Until May 2010, a total of more than 10,700 formalin-fixed and paraffin-embedded (FFPE) samples have been centrally collected, due to the efficient contributions of a large number of pathologists from the study sites in Germany.

Current research concepts focus on biomarker assessment in pretherapeutic core biopsies. The technologies include standard hematoxylin and eosin (H\&E) stainings, immunohistology and RNA-based techniques. In this review, we will describe examples for translational research approaches using the different technologies (fig. 1). All projects are controlled by the translational subboard.
The current standard approach in pathological biomarker assessment for diagnostic and predictive purposes is immunohistochemistry (IHC), i.e. the labeling of cellular proteins by antibodies and the subsequent microscopic evaluation by the pathologist. Immunohistochemical stains allow direct visualization of the protein-expressing cell population and the subcellular protein distribution. This makes IHC a powerful tool in qualitative differential diagnosis in surgical pathology. IHC also serves well for some predictive purposes, e.g. in estrogen receptor (ER) and HER2 expression analysis for prediction of the endocrine and trastuzumab response, respectively.

Most research applications of IHC are performed on tissue microarrays. This time- and cost-effective method allows the staining and evaluation of many tumor samples on a single tissue slide and allows high-throughput analysis of biomarkers using IHC, RNA in situ hybridization (RNA-ISH) or fluorescence in situ hybridization (FISH) [26]. The construction of tissue microarrays from core biopsies requires special processing. Before tissue microarray construction, the H\&E-stained tissue slides are reviewed and only cores containing more than $30 \%$ of tumor cells are chosen. The core biopsy is then cut from the paraffin block, rotated by $90^{\circ}$ and placed upright into a fresh paraffin block $[6,7]$. Using this technique, we successfully analyzed the expression of several antibodies, such as steroid HRs, HER2, and poly(ADP-ribose) polymerase (PARP) [27-30]. 


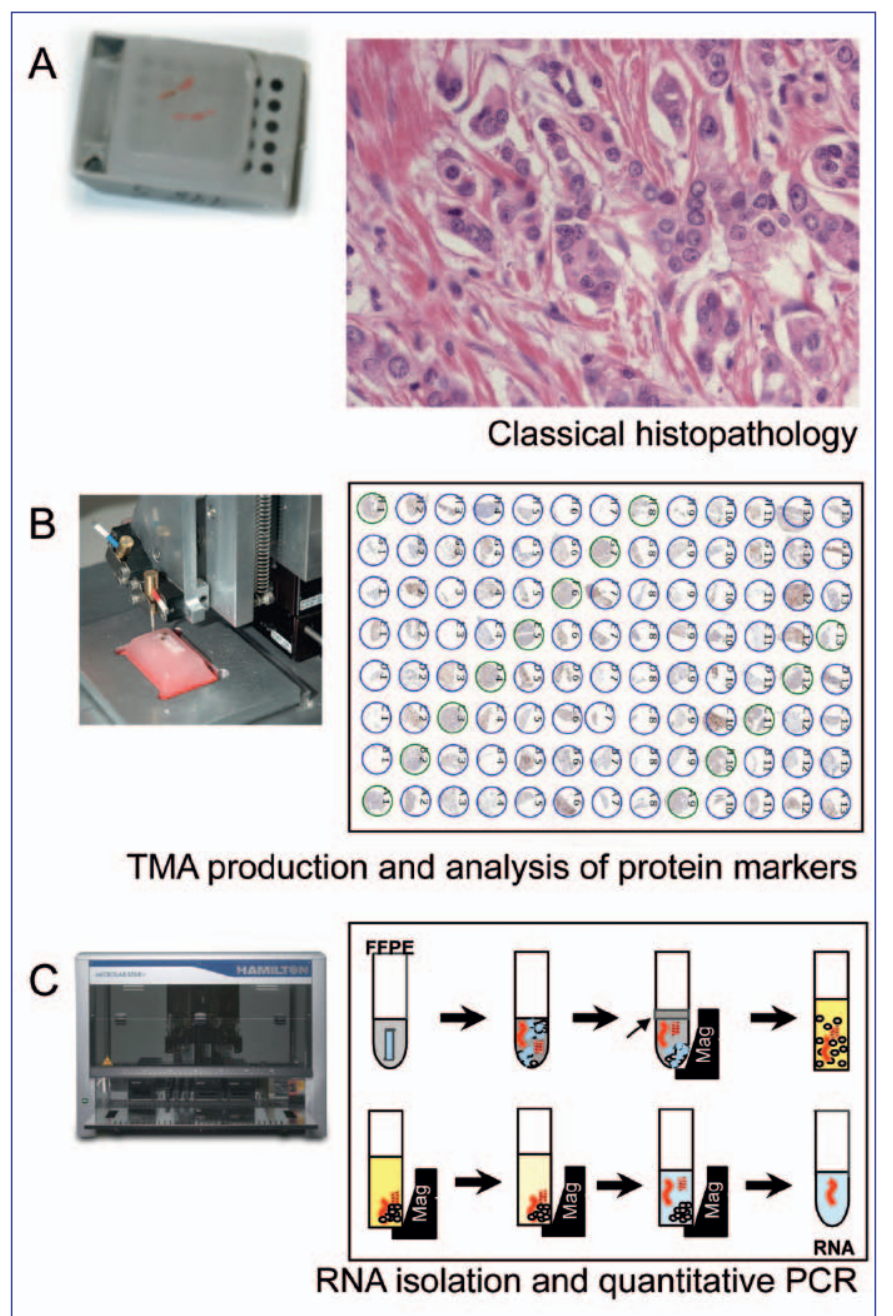

Fig. 1. Workflow for evaluation of tissue-based biomarkers in the neoadjuvant setting. Pretherapeutic FFPE core biopsies are evaluated by standard histopathology (A). Tissue microarrays can be produced by transferring the core biopsies to new acceptor paraffin blocks for evaluation of protein markers (B). RNA isolation from FFPE tissue is performed with the Siemens Versant system for marker analysis by quantitative RT-PCR.

\section{Evaluation of RNA Biomarkers from Neoadjuvant Samples}

In the last decades, targeted therapies have greatly changed the treatment of malignant disease, resulting in an increased demand for predictive biomarker assessment by pathologists. While human judgment seems adequate in qualitative, tissuebased assessment of biomarker expression, automated, standardized and quantitative methods provide the opportunity of detecting far more subtle and highly reproducible differences of biomarker expression.

The development of reliable techniques for the extraction of mRNA from FFPE tissue for use in quantitative reverse transcription-polymerase chain reaction (RT-PCR) greatly promoted research in this area. Recently, we and others have shown that expression analysis of established biomarkers as
ER, progesterone receptor (PR) and HER2 is feasible and reproducible using kinetic RT-PCR with fully automated extraction of RNA from FFPE tissue [31, 32]. Being both sensitive and reproducible, the technique has proven to be of practical value, e.g. the quantification of the T-cell related markers CD3D and CXCL9 for the prediction of response to neoadjuvant chemotherapy in breast cancer [28] or the assessment of prognosis in ovarian cancer [33].

Also, such techniques facilitate the evaluation of many different markers at a time, allowing the implementation of stable predictive or prognostic scoring algorithms that might ultimately support clinical decision making.

The development of fully automated RNA extraction systems with highly standardized protocols including reliable controls will further promote the application of predictive multi-gene assays. The performance of tests in decentralized molecular pathology laboratories avoids the transfer of tissue and will contribute to the wide application of quantitative biomarker assessment.

\section{Molecular Tumor Typing and Response to Neoadjuvant Chemotherapy}

There are several studies using gene expression profiles in breast cancer to define the molecular subtypes of luminal, HER2-positive and triple-negative tumors based on differences in tumor biology [34-36]. Data from preclinical studies show a functional interaction between HR and HER2 signaling $[37,38]$. We examined if the relation of estrogen receptor 1 (ESR1) and HER2 expression may influence the response to anthracycline/taxane-based neoadjuvant chemotherapy and DFS in dependence on molecular subtype.

For this reason, we established the hypothesis that this relationship might lead to differences in clinical behavior, in response to anthracycline/taxane-based chemotherapy and in DFS depending on the molecular subtype. Furthermore, it has been suggested that the subgroup of triple-negative tumors might show a mixture of different tumor characteristics [39]. We evaluated protein biomarkers using IHC and silverenhanced ISH on tissue microarrays of pretherapeutic core biopsies in a group of 116 participants of the GeparDuo study. We found significantly $(\mathrm{p}=0.044)$ different $\mathrm{pCR}$ rates between the different molecular subtypes. Patients with $\mathrm{HR}+/$ HER2 + or HR-/HER2 - tumors achieved higher pCR rates than those with HR+/HER2- tumors. The Ki67 labeling index was a significant $(\mathrm{p}=0.001)$ predictor of $\mathrm{pCR}$ in the whole study group and was associated with higher $\mathrm{pCR}$ rates among triple-negative carcinomas $(\mathrm{p}=0.006)$. In a multivariate analysis, biology-based tumor type ( $p=0.046$ for HR+/HER2+ vs. HR+/HER2-), Ki67 labeling index $(\mathrm{p}=0.028)$ and the treatment arm $(\mathrm{p}=0.036)$ were independent predictors of a $\mathrm{pCR}$. Regarding DFS, patients with HR+/HER2- and HR+/HER2+ tumors showed the best prognosis $(\mathrm{p}<0.0001)$ while the 

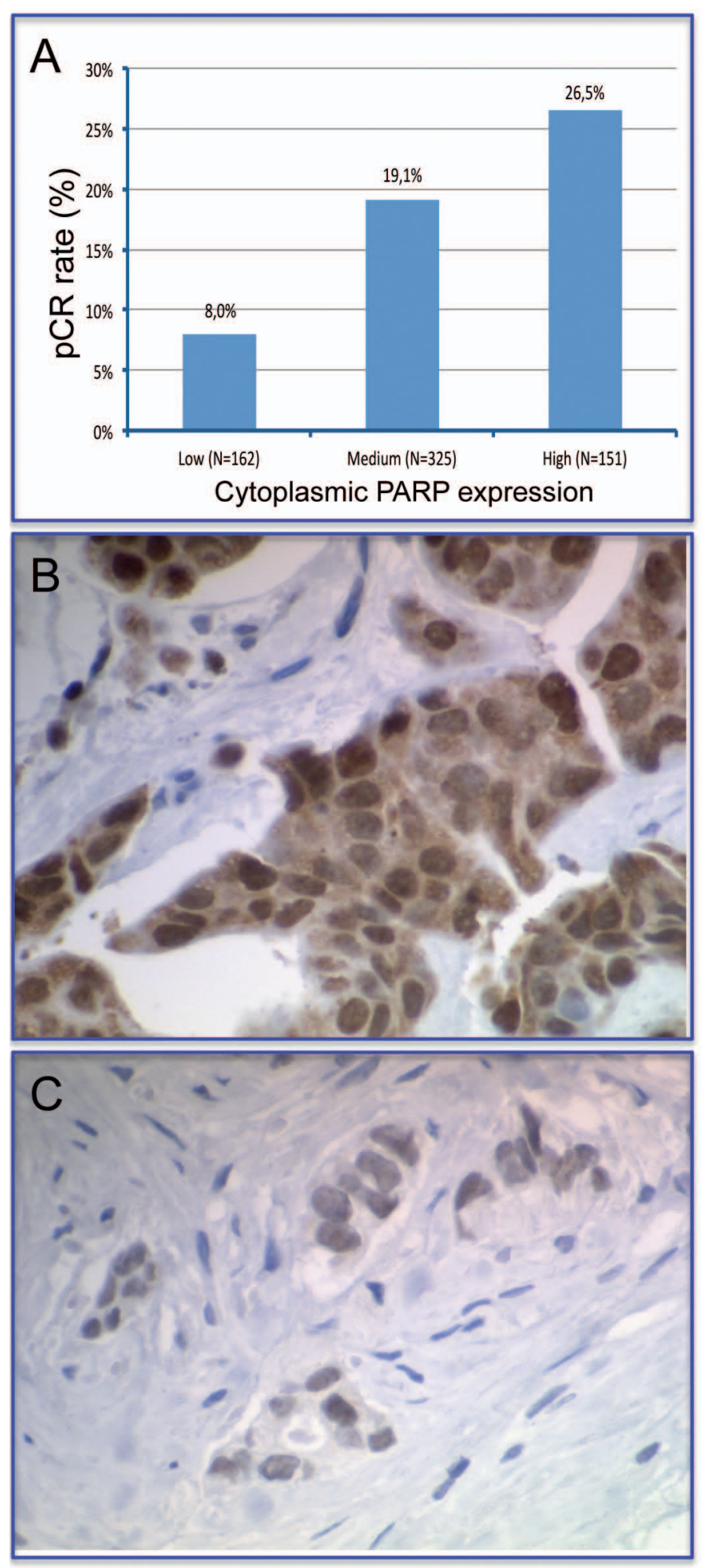

Fig. 2. Prediction of response to neoadjuvant chemotherapy by cytoplasmic expression of PARP. Tumors with low, intermediate or high cPARP expression have a significantly different response to neoadjuvant chemotherapy $(<0.0005)$ (A). Strong cytoplasmic expression of PARP (B). Negative cytoplasmic expression of PARP (C). biology-based tumor type was an independent prognostic factor $(\mathrm{p}<0.001)$. In contrast, patients with HR-/HER2+ tumors had the worst outcome. The HR+/HER2+ coexpressing carcinomas emerged as a group of tumors with a good response rate to neoadjuvant chemotherapy and a favorable prognosis. HR+/HER2- tumors had a good prognosis irrespective of $\mathrm{pCR}$, whereas patients with $\mathrm{HR}-/ \mathrm{HER}-$ and $\mathrm{HR}-/$ HER + tumors, especially if they had not achieved a pCR, had an unfavorable prognosis and were in need of additional treatment options.

\section{Expression of PARP as a Predictive Factor in the Neoadjuvant Setting}

PARPs are a family of several multifunctional enzymes that are activated through DNA strand breaks [40]. PARP activation leads to the synthesis of large branching chains of poly(ADP-ribose) polymers to target proteins by the use of nicotinamide adenine dinucleotide (NAD+). Its role in singlestrand breaks via the base excision pathway has been more extensively studied than its activation induced by single- or double-strand breaks [41-45]. Other relevant functions include PARP-dependent apoptosis and necrosis [46].

The potential role of PARP inhibitors as new anticancer agents is currently under research in several clinical studies on breast cancer and other malignancies [47-49]. We investigated the cytoplasmic (cPARP) and nuclear PARP (nPARP) expression by IHC in FFPE pre-therapeutical core biopsies from 638 patients of the GeparTrio trial (fig. 2). Stained slides were digitized and evaluated as virtual slides. We evaluated the intensity and the percentage of positive tumor cells, calculated the immunoreactive score (IRS) and defined 3 subgroups: IRS 0-2 (negative), IRS 3-4 (medium) and IRS 6-12 (high).

We found that cPARP expression was high in $23.7 \%$, intermediate in $50.9 \%$, and negative in $25.4 \%$ of tumors. High cPARP expression was significantly correlated with special tumor subtypes: non-lobular histology $(\mathrm{p}<0.001)$, undifferentiated grade $(\mathrm{p}<0.001)$, positive nodal status $(\mathrm{p}=0.049)$ and negative HR status $(\mathrm{p}<0.001)$. The $\mathrm{pCR}$ rate showed significant $(\mathrm{p}<0.001)$ correlations with cPARP expression $(26.5$, 19.1 , and $8.0 \%$ in patients with high, intermediate, or negative expression, respectively). In DFS $(p=0.0025)$ and overall survival $(\mathrm{p}=0.0022)$, high cPARP expression was a negative but not independent prognostic factor. We found no such correlations for nPARP expression. In conclusion, we showed that high cPARP expression correlates with an aggressive tumor pattern, a higher $\mathrm{pCR}$ rate, but also with unfavorable long-term prognosis. cPARP-positive breast cancer might therefore become a new relevant entity concerning the PARP inhibition therapy. 


\section{Neoadjuvant Chemotherapy, Inflammatory Infiltrates and Therapy Response}

Only $10-25 \%$ of patients achieve a pCR after neoadjuvant chemotherapy [50, 51]. Pretherapeutic core biopsies from these patients are a valuable source for the identification of biomarkers that may help to select patients that are likely to benefit from neoadjuvant treatment. In this setting, the pathological evaluation of therapy success serves as an in vivo assay of chemosensitivity [52].

Preclinical studies have shown that immunological response plays a crucial role in the elimination of tumor cells in response to cytotoxic therapy [53, 54]. It has been shown that anthracyclines induce immunologic response mediated by calreticulin and high-motility-group box 1 (HMGB-1).

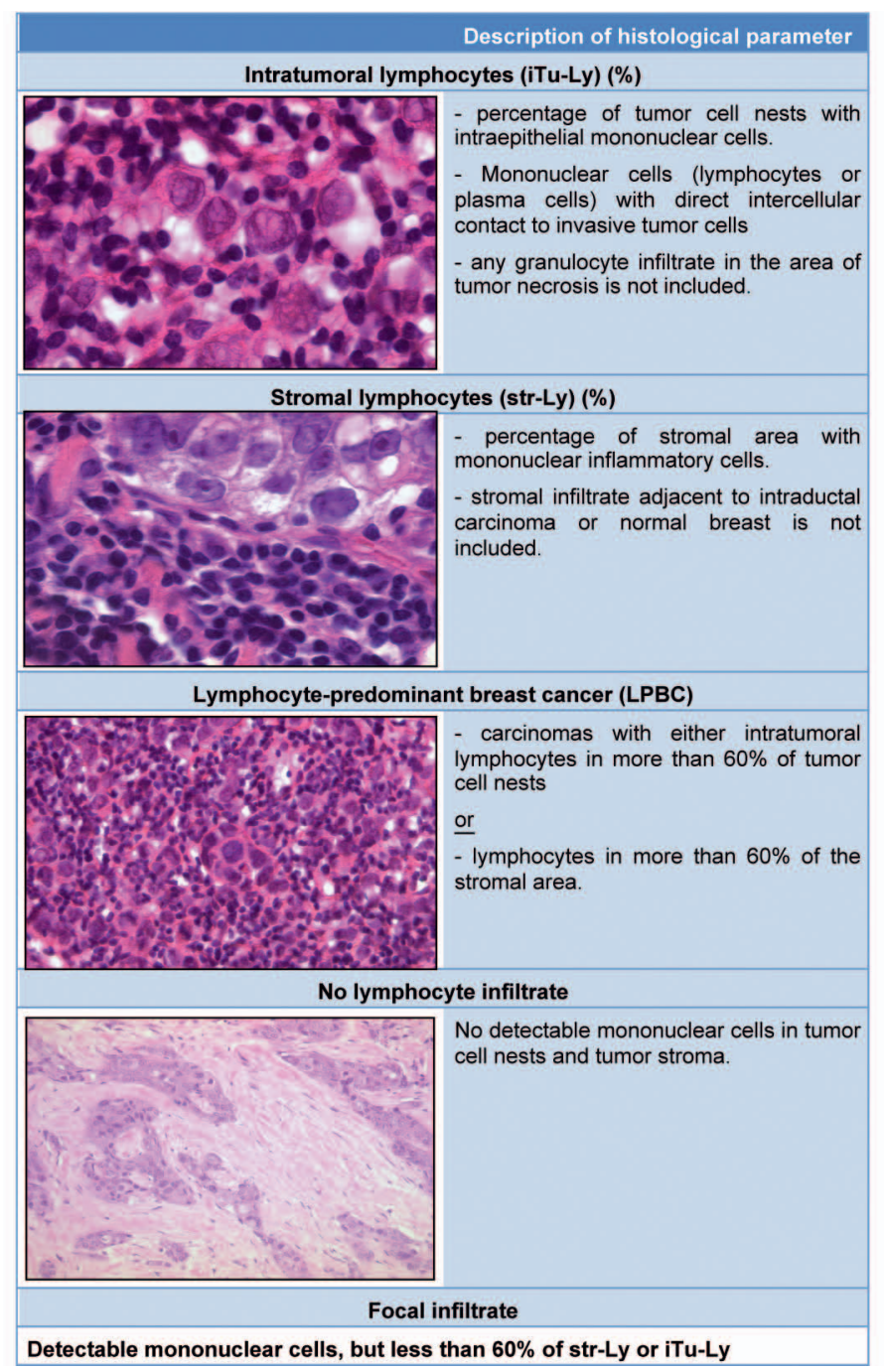

Fig. 3. Different types of immunological infiltrates in breast cancer; assessment by standard H\&E staining (modified from [28] with permission).
Toll-like receptor-4 (TLR4) mediates the response to microbial pathogens and to endogenous immunogenic signals released from dying tumor cells [55-57]. Polymorphisms of TLR4 have been shown to be an independent prognostic factor for therapy response [58]. Furthermore, a lymphocytic infiltrate has been shown to be a positive prognostic factor in various tumors [59-63]. To evaluate if the extent of immunologic response may enhance the effectiveness of chemotherapy, we studied the lymphocytic infiltrate (fig. 3) in pretherapeutic core biopsies as a predictor to neoadjuvant therapy. The population consisted of 1085 patients that were enrolled in the GeparDuo and GeparTrio neoadjuvant trials. We examined the presence and extent of lymphocytic infiltrates in both tumor cell nests and surrounding stroma. In GeparDuo, the pCR rate for all patients was $12.8 \%$ and $31 \%$ for patients with increased intratumoral lymphocytes $(\mathrm{p}<0.0005$, 2-tailed Fisher's test). A pCR rate of $41.7 \%$ could be observed among tumors defined as lymphocyte-predominant breast cancer with more than $60 \%$ of either stromal or intratumoral lymphocytes ( $p<0.0005$, Chi-square test). Tumors without lymphocytic infiltrate had a pCR rate of $2.8 \%$.

The results were validated using 840 cases from GeparTrio where lymphocytic infiltrate was a strong predictor of $\mathrm{pCR}$ in univariate $(p<0.0005)$ and multivariate analysis $(p=0.001)$.

As a basis for the implementation of predictive gene expression signatures that are based on immune response, molecular markers of lymphocyte recruitment and infiltration were examined by kinetic RT-PCR on FFPE core biopsies.

\section{Conclusions}

Neoadjuvant therapy offers an excellent tool to identify markers for pCR prediction. However, $\mathrm{pCR}$ is a predictive factor for DFS and overall survival mainly for HER2+ (non-luminal), triple-negative and some luminal B tumors, but not for luminal A or luminal B (HER2+) tumors. The neoadjuvant setting is suitable for the development of new biomarkers, and the current technologies allow the investigation of protein and RNA biomarkers using tissue microarrays and standardized RT-PCR approaches. The molecular tumor types and immunological infiltrates are important and independent predictors of therapy response. New markers such as cPARP expression might be important for the prediction of response to established and new targeted therapies.

\section{Disclosure Statement}

There is no conflict of interests that could be perceived as prejudicing the impartiality of the research reported. 


\section{References}

1 National Cancer Institute: Surveillance Epidermiology and End Results 2008. www.seer.cancer.gov.

2 Jemal A, Siegel R, Xu J, et al.: Cancer statistics, 2010. CA Cancer J Clin 2010;60:277-300.

3 Gesellschaft der epidemiologischen Krebsregister in Deutschland e.V.: Atlas der Krebsinzidenz und Krebsmortalität 2010. www.gekid.de/.

$\checkmark 4$ Mauri D, Pavlidis N, Ioannidis J, et al.: Neoadjuvant versus adjuvant systemic treatment in breast cancer: a meta-analysis. J Natl Cancer Inst 2005;97:188-194.

5 Kaufmann M, Hortobagyi GN, Goldhirsch A, et al.: Recommendations from an international expert panel on the use of neoadjuvant (primary) systemic treatment of operable breast cancer: an update. J Clin Oncol 2006;24:1940-1949.

6 Arbeitsgemeinschaft Gynäkologische Onkologie: www.ago-online.de/g ('Leitlinien').

7 Kuerer HM, Newman LA, Smith TL, et al.: Clinical course of breast cancer patients with complete pathologic primary tumor and axillary lymph node response to doxorubicin-based neoadjuvant chemotherapy. J Clin Oncol 1999;17:460-469.

8 von Minckwitz G, Blohmer JU, Raab G, et al.: In vivo chemosensitivity-adapted preoperative chemotherapy in patients with early-stage breast cancer: the GeparTrio pilot study. Ann Oncol 2005;16:1556-1563.

$\checkmark$ von Minckwitz G, Raab G, Caputo A, et al.: Doxorubicin with cyclophosphamide followed by docetaxel every 21 days compared with doxorubicin and docetaxel every 14 days as preoperative treatment in operable breast cancer: the GeparDuo study of the German Breast Group. J Clin Oncol 2005;23:2676-2685.

10 Von Minckwitz G, Kaufmann M, Kümmel S, et al.: Correlation of various pathologic complete response (pCR) definitions with long-term outcome and the prognostic value of $\mathrm{pCR}$ in various breast cancer subtypes: Results from the German neoadjuvant meta-analysis. J Clin Oncol 2011; 29(suppl):abstr 1028.

11 Untch M, Fasching AP, Konecny EG, et al. Pathological complete response after neoadjuvant chemotherapy plus trastuzumab predicts favorable survival in HER2-overexpressing breast cancer - Results from the TECHNO trial of the AGO and GBG study groups. Cancer Res 2010;70(suppl 2):abstr P1-11-03, pg 165s.

12 Liedtke C, Mazouni C, Hess KR, et al.: Response to neoadjuvant therapy and long-term survival in patients with triple-negative breast cancer. J Clin Oncol 2008;26:1275-1281.

13 Von Minckwitz G, Untch M, Nüesch E, et al.: Impact of treatment characteristics on response of different breast cancer phenotypes: pooled analysis of the German neo-adjuvant chemotherapy trials. Breast Cancer Res Treat 2011;125:145-156.

14 Von Minckwitz, Kümmel S, Vogel P, et al.: Neoadjuvant vinorelbine-capecitabine versus docetaxel-doxorubicin-cyclophosphamide in early nonresponsive breast cancer: phase III randomized GeparTrio trial. J Natl Cancer Inst 2008;100:542551.

15 Von Minckwitz, Kümmel S, Vogel P, et al.: Intensified neoadjuvant chemotherapy in early-responding breast cancer: phase III randomized GeparTrio study. J Natl Cancer Inst 2008;100:552-562.
16 Huober J, von Minckwitz G, Denkert C, et al.: Effect of neoadjuvant anthracycline-taxane-based chemotherapy in different biological breast cancer phenotypes: overall results from the GeparTrio study. Breast Cancer Res Treat 2010;124:133-140.

17 Von Minckwitz G, Eidtmann H, Rezai M, et al.: Neoadjuvant chemotherapy with or without bevacizumab: primary efficacy endpoint analysis of the GeparQuinto study (GBG 44). Cancer Res 2011;70(suppl 2):SABCS10 abstr S4-6.

18 Gerber B, Eidtmann H, Rezai M, et al.: Neoadjuvant bevacizumab and anthracycline-taxane-based chemotherapry in 686 triple-negative primary breast cancers: Secondary endpoint analysis of the GeparQuinto study (GBG 44). J Clin Oncol 2011;29:(suppl):abstr 1006.

19 Bear HD, Tang P, Rastogi P, et al.: The effect on pCR of bevacizumab and/or antimetabolites added to standard neoadjuvant chemotherapy: NSABP protocol B-40. J Clin Oncol 2011;29(suppl):abstr LBA1005.

20 Untch M, Loibl S, Bischoff J, et al.: Lapatinib vs trastuzumab in combination with neoadjuvant anthracycline-taxane-based chemotherapy: primary efficacy endpoint analysis of the GeparQuinto study (GBG 44). Cancer Res 2010;70(suppl 2):SABCS10 abstr S3-1.

21 Holmes FA, Nagarwala YM, Espina VA, et al.: Correlation of molecular effects and pathologic complete response to preoperative lapatinib and trastuzumab, separately and combined prior to neoadjuvant breast cancer chemotherapy. J Clin Oncol 2011;29(suppl):abstr 506.

22 Loibl S, Bruey J, von Minckwitz G, et al.: Validation of p95 as a predictive marker for trastuzumabbased therapy in primary HER2-positive breast cancer: A translational investigation from the neoadjuvant GeparQuattro study. J Clin Oncol 2011;29(suppl):abstr 530.

23 Perez EA, Dueck AC, Reinholz MM, et al.: Effect of PTEN protein expression on benefit to adjuvant trastuzumab in early-stage HER2+ breast cancer in NCCTG adjuvant trial N9831. J Clin Oncol 2011;29(suppl):abstr 10504.

24 Dave B, Migliaccio I, Gutierrez MC, et al.: Loss of phosphatase and tensin homolog or phosphoinositol-3 kinase activation and response to trastuzumab or lapatinib in human epidermal growth factor receptor 2-overexpressing locally advanced breast cancers. J Clin Oncol 2011;29:166-173.

25 Huober J, Loibl S, Untch M, et al.: New molecular biomarkers for resistance to trastuzumab-based therapy in primary HER2 positive breast cancer a translational investigation from the neoadjuvant GeparQuattro study. Cancer Res 2010;70(suppl 2):SABCS10 abstr PD02 06

26 Kuefer R, Hofer MD, Gschwend JE, Rubin MA: Tissue-Microarrays. Urologe A 2004;43:659-668.

27 Darb-Esfahani S, Loibl S, Müller BM, et al.: Identification of biology-based breast cancer types with distinct predictive and prognostic features: role of steroid hormone and HER2 receptor expression in patients treated with neoadjuvant anthracycline/ taxane-based chemotherapy. Breast Cancer Res 2009;11:R69.

28 Denkert C, Loibl S, Roller M, et al.: Tumor-associated lymphocytes as an independent predictor of response to neoadjuvant chemotherapy in breast cancer. J Clin Oncol 2010;28:105-113.
29 Noske A, Loibl S, Darb-Esfahani S, et al.: Comparison of different approaches for assessment of HER2 expression on protein and mRNA level: prediction of chemotherapy response in the neoadjuvant GeparTrio trial (NCT00544765). Breast Cancer Res Treat 2011;126:109-117.

30 von Minckwitz G, Müller BM, Loibl S, et al.: Cytoplasmic PARP expression is predictive and prognostic in patients with breast cancer treated with neoadjuvant chemotherapy. J Clin Oncol 2011; 29:2150-2157.

31 Bohmann K, Hennig G, Rogel U, et al.: RNA extraction from archival formalin-fixed paraffinembedded tissue: a comparison of manual, semiautomated, and fully automated purification methods. Clin Chem 2009;55:1719-1727.

32 Müller BM, Kronenwett R, Hennig G, et al.: Quantitative determination of estrogen receptor, progesterone receptor, and HER2 mRNA in formalinfixed paraffin-embedded tissue - a new option for predictive biomarker assessment in breast cancer. Diagn Mol Pathol 2011;20:1-10.

33 Darb-Esfahani S, Wirtz RM, Sinn BV, et al.: Estrogen-receptor 1 mRNA is a prognostic factor in ovarian carcinoma: determination by kinetic RTPCR in formalin-fixed paraffin-embedded tissue. Endocr Relat Cancer 2009;16:1229-1239.

- 34 Sørlie T, Perou CM, Tibshirani R, et al.: Gene expression patterns of breast carcinomas distinguish tumor subclasses with clinical implications. Proc Natl Acad Sci USA 2001;98:10869-10874.

35 Sorlie T, Wang Y, Xiao C, et al.: Distinct molecular mechanisms underlying clinically relevant subtypes of breast cancer: gene expression analyses across three different platforms. BMC Genomics 2006;(7):127.

36 Calza S, Hall P, Auer G, et al.: Intrinsic molecular signature of breast cancer in a populationbased cohort of 412 patients. Breast Cancer Res 2006;8:R34.

37 Ciocca DR, Gago FE, Fanelli MA, et al.: Coexpression of steroid receptors (estrogen receptor alpha and/or progesterone receptors) and Her-2/ neu: Clinical implications. J Steroid Biochem Mol Biol 2006;102:32-40.

38 Prat A, Baselga J: The role of hormonal therapy in the management of hormonal-receptor-positive breast cancer with coexpression of HER2. Nat Clin Pract Oncol 2008;5:531-542.

39 Rakha EA, Tan DS, Foulkes WD, et al.: Are triple-negative tumours and basal-like breast cancer synonymous? Breast Cancer Res 2007;9:404.

40 Chalmers AJ: The potential role and application of PARP inhibitors in cancer treatment. Br Med Bull 2009;89:23-40.

41 Bernstein C, Bernstein H, Payne CM, et al.: DNA repair/pro-apoptotic dual-role proteins in five major DNA repair pathways: fail-safe protection against carcinogenesis. Mutat Res 2002;511:145178.

42 Fisher AEO, Hochegger H, Takeda S, et al.: Poly(ADP-ribose) polymerase 1 accelerates singlestrand break repair in concert with poly(ADPribose) glycohydrolase. Mol Cell Biol 2007;27: 5597-5605.

43 Audebert M, Salles B, Calsou P: Involvement of poly(ADP-ribose) polymerase-1 and XRCC1/ DNA ligase III in an alternative route for DNA double-strand breaks rejoining. J Biol Chem 2004;279:55117-55126. 
44 Chang P, Jacobson MK, Mitchison TJ: Poly(ADPribose) is required for spindle assembly and structure. Nature 2004;432:645-649.

-45 Kim MY, Mauro S, Gevry N, et al.: NAD+dependent modulation of chromatin structure and transcription by nucleosome binding properties of PARP-1. Cell 2004;119:803-814.

46 Woodhouse BC, Dianov GL: Poly ADP-ribose polymerase-1: An international molecule of mystery. DNA Repair 2008; 7:1077-1086.

47 Rowe BP, Glazer PM: Emergence of rationally designed therapeutic strategies for breast cancer targeting DNA repair mechanisms. Breast Cancer Res 2010;12:203.

48 O'Shaughnessy J, Osborne C, Pippen JE, et al.: Iniparib plus chemotherapy in metastatic triple-negative breast cancer. N Engl J Med 2011;364:205-214.

-49 Annunziata CM, O'Shaughnessy J: Poly(ADPribose) polymerase as a novel therapeutic target in cancer. Clin Cancer Res 2010;16:4517-4526.

50 Smith IC, Heys SD, Hutcheon AW, et al.: Neoadjuvant chemotherapy in breast cancer: significantly enhanced response with docetaxel. J Clin Oncol 2002;20:1456-1466.

51 Fisher B, Bryant J, Wolmark N, et al.: Effect of preoperative chemotherapy on the outcome of women with operable breast cancer. J Clin Oncol 1998;16:2672-2685.
Rastogi P, Anderson SJ, Bear HD, et al.: Preoperative chemotherapy: updates of National Surgical Adjuvant Breast and Bowel Project Protocols B-18 and B-27. J Clin Oncol 2008;26:778-785.

53 Zitvogel L, Kroemer G: The immune response against dying tumor cells: avoid disaster, achieve cure. Cell Death Differ 2008;15:1-2.

54 Apetoh L, Ghiringhelli F, Tesniere A, et al.: The interaction between HMGB1 and TLR4 dictates the outcome of anticancer chemotherapy and radiotherapy. Immunol Rev 2007;220:47-59.

55 Apetoh L, Tesniere A, Ghiringhelli F, et al.: Molecular interactions between dying tumor cells and the innate immune system determine the efficacy of conventional anticancer therapies. Cancer Res 2008;68:4026-4030.

56 Zitvogel L, Apetoh L, Ghiringhelli F, et al.: Immunological aspects of cancer chemotherapy. Nat Rev Immunol 2008;8:59-73.

57 Zitvogel L, Apetoh L, Ghiringhelli F, et al.: The anticancer immune response: indispensable for therapeutic success? J Clin Invest 2008;118:19912001.

58 Apetoh L, Ghiringhelli F, Tesniere A, et al.: Tolllike receptor 4-dependent contribution of the immune system to anticancer chemotherapy and radiotherapy. Nat Med 2007;13:1050-1059.
59 Pagès F, Berger A, Camus M, et al.: Effector memory T cells, early metastasis, and survival in colorectal cancer. N Engl J Med 2005;353:2654-2666.

60 Zhang L, Conejo-Garcia JR, Katsaros D, et al.: Intratumoral $\mathrm{T}$ cells, recurrence, and survival in epithelial ovarian cancer. $\mathrm{N}$ Engl $\mathrm{J}$ Med 2003:348:203-213.

61 DeNardo DG, Coussens LM: Inflammation and breast cancer. Balancing immune response: crosstalk between adaptive and innate immune cells during breast cancer progression. Breast Cancer Res 2007;9:212.

62 Aaltomaa S, Lipponen P, Eskelinen M, et al.: Lymphocyte infiltrates as a prognostic variable in female breast cancer. Eur J Cancer 1992;28:859864.

63 Schmidt M, Böhm D, von Törne C, et al.: The humoral immune system has a key prognostic impact in node-negative breast cancer. Cancer Res 2008;68:5405-5413. 